\title{
Research on the Correlation Effect Between Industrial Agglomeration, Technological Innovation and Environment
}

\author{
Rui Gao \\ School of Economics and Management \\ Nanjing University of Science and Technology \\ Nanjing, China
}

\author{
Zhijun Yan \\ School of Economics and Management \\ Nanjing University of Science and Technology \\ Nanjing, China
}

\begin{abstract}
This paper considers that there is an inseparable interaction between technological innovation and industrial agglomeration, and it plays a role that cannot ignored in energy conservation and emission reduction, it has added the technical innovation index while studying the mechanism of industrial agglomeration on the environment. Mainly using panel data from 30 provinces (excluding Tibet, Hong Kong, Macao and Taiwan) from 1998 to 2014 , empirically analyze the relationship between industrial agglomeration, technological innovation and environmental pollution under the new normal.
\end{abstract}

Keywords-correlation effect; industrial agglomeration; technological innovation

\section{INTRODUCTION}

Since the reform and opening up, industrial agglomeration and expansion inevitably exacerbated pollutant emissions, resulting in a deteriorating environment. Scholars have gradually shifted their research focus from the positive externalities of agglomeration to environmental pollution. However, since 2009, China has begun to focus on the economic development, while paying attention to environmental protection, improving quality and efficiency, and encouraging new economic developments, the status quo of environmental pollution has changed.

Taking the main pollutants in the exhaust gas as an example, according to the " 2015 China Environmental Status Bulletin", the total amount of sulfur dioxide emissions in 2015 was 18.591 million tons, down $5.8 \%$ from 2014 and $18.0 \%$ from 2010; nitrogen oxide emissions The total amount was 18.518 million tons, down $10.9 \%$ from 2014 and down $18.6 \%$ from 2010. Obviously, the data shows that environmental pollution has improved in 2015, Has the role of industrial agglomeration changed?

This paper has carried out research based on the above questions. Considering that there is an inseparable interaction between technological innovation and industrial agglomeration, and it plays a role that cannot ignore in energy conservation and emission reduction, it has added the technical innovation index while studying the mechanism of industrial agglomeration on the environment. Mainly using panel data from 30 provinces (excluding Tibet, Hong Kong,
Macao and Taiwan) from 1998 to 2014, empirically analyze the relationship between industrial agglomeration, technological innovation and environmental pollution under the new normal. This research is conducive to the formulation of China's energy-saving emission reduction targets and policies, improving the current situation of frequent smog, and has important practical significance for the rapid and rapid development of China's economy in contemporary society.

\section{ANALYSIS METHOD AND ORIGIN OF DATA}

\section{A. Pollution Discharge (POL)}

The exhaustive pollutants, wastewater pollutants and solid pollutants in the real world are huge and difficult to measure. According to relevant literatures, most scholars use industrial sulfur dioxide emissions as indicators to measure pollution emissions (POL). In combination with reality, China is a country with a large amount of sulfur dioxide emissions, sulfur dioxide is also a major component of atmospheric pollutants, and relevant data is easy to collect. Therefore, this paper also uses this measurement method.

\section{B. Industrial Agglomeration (IAG)}

There are many indicators for the degree of industrial agglomeration. Today, the measurement indicators adopted by scholars at home and abroad are location entropy, which can also eliminate the regional scale difference factors, and can better measure the spatial distribution of factors in a certain region, reflecting a certain the degree of specialization in the industrial sector. Yang Renfa (2013), Yuan Yijun, Xie Ronghui (2015), Huang Juan, Wang Mingjin (2016) and others used the location entropy index to calculate the degree of industrial agglomeration in the industrial structure research. This paper draws on the ideas of predecessors, measures the industrial agglomeration by the size of location entropy, and selects the industrial total output value calculating location quotient.

\section{Technology Innovation (INN)}

Industrial agglomeration has the effect of promoting knowledge and technology spillovers, which can promote 
more enterprises in the agglomeration area to innovate, and technological innovation plays an invaluable role in energy conservation and emission reduction. We know that the most direct expression of technological innovation is patents, but there is a time lag between patent application and acceptance. Considering the availability of data, this paper selects the domestic patent application acceptance as an indicator to measure technological innovation.

\section{Other Control Variables}

1) Environmental awareness (ENC): With the development of the times, the importance of environmental awareness is self-evident. The strength of environmental awareness of the government and the public directly linked to the intensity of local environmental pollution. Therefore, this paper ranks environmental awareness as the first of other control variables, and the proportion of industrial environmental pollution control investment in GDP over the years measures the degree to which the local government pays attention to the environment.

2) Dustrial Structure (STR): Promoting the optimization and upgrading of industrial structure is a long-term priority in China's economic and social development process, accelerating the transformation of labor-intensive industries to capital-driven and technology-intensive industries. I selected the proportion of the tertiary industry as a measure of the industrial structure in this paper.

3) Foreign Direct Investment (FDI): There are not many documents on the relationship between FDI and environmental pollution. As for today, it divided into two factions: some scholars believe that FDI has intensified environmental pollution and even proposed the famous "pollution". At the same time, other scholars believe that FDI will not only pollute the environment, but also contribute to the improvement of environmental pollution. Based on this, this paper will use the actual use of FDI in each province to measure.

4) Economic development level (PGDP): China's new economic normality began in 2009 (Li Yang, 2014). Since then, China's economic development has entered a new era of shifting speed, improving quality and increasing efficiency. Then, under the new normal, whether China's economic development level has a new feature on the regional environment is worth studying. This paper selects the per capita GDP of each province as a measure to carry out the regression.
At present, most of the literatures focus on the two-way research on industrial agglomeration and environmental pollution, or the one-way research perspective of environmental regulation on technological innovation. The research on industrial agglomeration, technological innovation and environmental issues is relatively rare, and only near it only began to appear in a year or two.

Based on the previous literature, this paper proposes hypotheses and conducts research in the following aspects:

- H1: Due to the strong correlation between industrial agglomeration and economic growth, it assumed that the relationship between industrial agglomeration and regional environment in China also follows the environmental Kuznets curve (EKC).

- H2: Construct a theoretical model of industrial agglomeration and technological innovation for environmental pollution and conduct regression analysis. It suspected that the interaction between technological innovation and industrial agglomeration has a negligible impact on the environment.

- H3: Because the existing literature tells us that there is a process of interaction coupling between industrial agglomeration and regional environment, the evolution from negative externality to positive externality requires a threshold. Then this paper guesses that technological innovation will affect this threshold.

Based on the above assumptions, this paper will construct a series of theoretical models between industrial agglomeration, technological innovation and environment, and empirically study the specific correlation effects between industrial agglomeration, technological innovation and environment, especially in which technological innovation may play a role. The important threshold function.

This paper selects the panel data of 30 provinces (excluding Tibet, Hong Kong, Macao and Taiwan) from 1998 to 2014 as a sample for analysis. The data required are from wind information, the China Environmental Statistics Yearbook, and the Chinese industrial economy. Statistical Yearbook, China Science and Technology Statistical Yearbook, China Statistical Yearbook, and statistical yearbooks of provinces and cities (autonomous regions), each variable (sample size is 510) Descriptive statistics shown in "Table I".

TABLE I. DESCRIPTIVE STATISTICS

\begin{tabular}{|c|c|c|c|c|c|c|}
\hline Index & variable & average & Maximum & Minimum & Standard deviation & Statistics of J-B \\
\hline Pollution emission & POL & 72.088 & 225.89 & 2.00 & 45.037 & 30.727 \\
\hline Industrial Agglomeration & IAG & 1.136 & 94.45 & 0.1124 & 4.146 & 5397038 \\
\hline Technical innovation & INN & 25290 & 504500 & 124 & 55017 & 21356.6 \\
\hline Environmental awareness & ENC & 1.155 & 4.16 & 0.0189 & 0.706 & 297.33 \\
\hline industrial structure & STR & 40.464 & 77.9 & 11.7 & 7.74 & 1819.12 \\
\hline Foreign direct investment & FDI & 3095191 & 80351686 & 14413 & 5249096 & 183742 \\
\hline Level of economic development & PGDP & 23575 & 105231 & 2364 & 19917 & 302.7 \\
\hline
\end{tabular}


Based on previous studies, this paper constructs a panel model of industrial agglomeration, technological innovation and environmental pollution (in order to avoid heteroscedasticity, this paper adopts a logarithmic model), and introduces the squared term of industrial agglomeration and industry based on linear model. An interaction between agglomeration and technological innovation, and a systematic regression analysis.

The specific model constructed as follows:

$\ln \mathrm{POL}_{\mathrm{it}}=\alpha_{0}+\alpha_{1} \ln \mathrm{IAG}_{\mathrm{it}}+\alpha_{2} \ln \mathrm{INN}_{\mathrm{it}}+\alpha_{3} \ln \mathrm{ENC}_{\mathrm{it}}+\alpha_{4} \ln \mathrm{STR}_{\mathrm{it}}+$ $\alpha_{5} \operatorname{lnFDI}_{\mathrm{it}}+\alpha_{6} \operatorname{lnPGDP}_{\mathrm{it}}+\varepsilon_{\mathrm{it}}(1)$

In the formula (1), i represents the region, $t$ represents the time, the interpreted variable POL represents the degree of environmental pollution, the explanatory variables are IAG (industrial agglomeration) and INN (technical innovation); other control variables are ENC (environmental awareness), STR (industrial structure), FDI (foreign direct investment) and PGDP (economic development level); $\alpha 0$ represents constant term, $\alpha 1$ to $\alpha 6$ are coefficients of each variable respectively, $\varepsilon_{\text {it }}$ is a random error term.

As a simple basic model:

(1)Only considers the linear relationship between industrial agglomeration, technological innovation and other control variables and environmental pollution. It will not described in detail, and the subsequent models will developed on this basis.

$\ln P O L i t=\alpha 0+\alpha 1 \ln I A G i t+\alpha 2 \ln I N N i t+\alpha 3 \ln E N C i t+\alpha 4 \ln S \mathrm{~T}$ Rit $+\alpha 5 \ln F D I i t+\alpha 6 \ln P G D P i t+\alpha 7 \ln P G D P 2 i t+\varepsilon i t \quad(2)$

(2) Introduce the squared term of per capita GDP (PGDP) and verify the authenticity of the environmental Kuznets curve (EKC) (hypothesis 1: H1) to further explain the relationship between industrial agglomeration and environmental pollution.

$\ln \mathrm{POLit}=\alpha 0+\alpha 1 \ln \mathrm{AAGit}+\alpha 2 \ln \mathrm{NNNit}+\alpha 3 \ln \mathrm{ENCit}+\alpha 4 \ln \mathrm{ST}$ Rit $+\alpha 5 \ln F D$ iit $+\alpha 6 \ln P G D P i t+\alpha 7 \ln I A G 2$ it $+\varepsilon i t \quad(3)$

(3) In the formula, the squared term of per capita GDP in (2) changed to the square of industrial agglomeration (IAG2) to verify whether there is a nonlinear relationship between industrial agglomeration and environmental pollution. The degree of agglomeration is different and the "inverted Ushaped" curve relationship is presented, which is also consistent with the environmental Kuznets curve (verification $\mathrm{H} 2$ ).

$\ln P O L i t=\alpha 0+\alpha 1 \ln I A G i t+\alpha 2 \ln I N N i t+\alpha 3 \ln E N C i t+\alpha 4 \ln S \mathrm{~T}$ Rit $+\alpha 5 \ln F D I i t+\alpha 6 \ln P$ GDPit $+\alpha 7 \ln ($ IAG $\cdot$ INN)it+cit (4)

(4) Based on the formula (1), introduce the interaction term of industrial agglomeration and technological innovation (IAG·INN), and study how the correlation effect between the two will affect the environmental pollution (further verify $\mathrm{H} 2$ ).

$\ln P O L i t=\alpha 0+\alpha 1 \ln I A G i t+\alpha 2 \ln I N N i t+\alpha 3 \ln E N C i t+\alpha 4 \ln S \mathrm{~T}$ Rit $+\alpha 5 \ln$ FDIit $+\alpha 6 \ln$ PGDPit $+\alpha 7 \ln I A G 2$ it $+\alpha 8 \ln ($ IAG $\cdot$ INN)it $+\varepsilon$ it (5)

(5) Introduce the squared term of industrial agglomeration (IAG2) and the interaction item of industrial agglomeration and technological innovation (IAG.INN), and study whether the factor of technological innovation will affect the inflection point of industrial agglomeration to improve the degree of environmental pollution, that is, "inverted U" Threshold value of the curve (verify H3).

$\ln P O L i t=\alpha 0+\alpha 1 \ln I A G i t+\alpha 2 \ln I N N i t+\alpha 3 \ln E N C i t+\alpha 4 \ln S \mathrm{~T}$ Rit $+\alpha 5 \ln F D$ it $+\alpha 6 \ln$ PGDPit $+\alpha 7 \ln$ PGDP2it $+\alpha 8 \ln$ IAG2it $+\alpha 91$ $\mathrm{n}(\mathrm{IAG} \cdot \mathrm{INN})$ it+eit (6)

(6) Add the squared item of GDP per capita, the squared item of industrial agglomeration and the interaction items of industrial agglomeration and technological innovation into the model (1), and introduce all the control variables to consider the goodness and stability of the final model.

\section{ANALYSIS OF REGRESSION RESULTS}

Because of the limited sample size of the problem we are studying, I also refer to Woodridge's view: He thinks that the fixed effect model is the most suitable for macro data, so this paper chooses the fixed variable intercept model. The regression results are shown in the "Table II".

TABLE II. PANEL DATA REgRESSION RESUlTS

\begin{tabular}{|c|c|c|c|c|c|c|}
\hline Model & (1) & (2) & (3) & (4) & (5) & (6) \\
\hline constant term & 3.481236 & $-8.69168 * * *$ & 0.879312 & $4.186394 * *$ & $5.495566^{* *}$ & -6.134226 \\
\hline $\ln I A G$ & $0.003104 * * *$ & $0.011841 * * *$ & $0.1188^{* * *}$ & $0.549958 * * *$ & $0.106990 * * *$ & $0.977419 * * *$ \\
\hline $\ln I N N$ & $-0.160097 * * *$ & $-0.156663^{* * * *}$ & $-0.155778 * * *$ & -0.179011 *** & $-0.191877 * *$ & -0.188850 ** \\
\hline $\operatorname{lnSTR}$ & $-0.782947 * * *$ & $-0.633764 * * *$ & $-0.727434 * * *$ & $-0.622918 * * *$ & $-0.665524 * * *$ & $-0.618221 * * *$ \\
\hline $\ln F D I$ & -0.024508 & -0.041477 & -0.030274 & 0.032701 & 0.009476 & 0.005585 \\
\hline $\ln P G D P$ & $0.238900 * * *$ & $15.29800^{*}$ & $1.103631 * * *$ & $0.069525 * * *$ & $-0.140901^{* *}$ & 5.038741 \\
\hline $\ln P G D P^{2}$ & & $-1.603951 * * *$ & & & & -0.579471 \\
\hline $\ln I A G^{2}$ & & & $-0.2547 * * *$ & & $-0.139890^{* * *}$ & $-0.122454 * *$ \\
\hline $\ln (I A G \cdot I N N)$ & & & & $-0.045592 * * *$ & $-0.059558 * * *$ & $-0.059343 * * *$ \\
\hline sample size & 510 & 510 & 502 & 510 & 510 & 510 \\
\hline$R^{2}$ & 0.814205 & 0.817741 & 0.808983 & 0.829651 & 0.831623 & 0.831976 \\
\hline Adjusted $R^{2}$ & 0.800486 & 0.803869 & 0.794194 & 0.816685 & 0.818424 & 0.818419 \\
\hline The value of $D W$ & 1.121133 & 1.127150 & 1.140156 & 1.220086 & 1.221911 & 1.219726 \\
\hline
\end{tabular}


In the above table, a simple linear model (1) shows that an increase in industrial agglomeration (IAG) will increase sulfur dioxide emissions. Similarly, an increase in technological innovation will also reduce sulfur dioxide emissions with a coefficient of -0.16 and significant variables. The positive role of technological innovation in energy conservation and emission reduction. Other variables such as FDI, the test results show that the variables are not significant and negatively correlated with sulfur dioxide emissions, which is inconsistent with the facts, indicating that the linear model is unreasonable.

Model (2) introduced the squared term of per capita GDP (PGDP) based on model (1). The model goodness of fit did not decrease, and the variables passed the $1 \%$ significance level test. The $\ln$ PGDP2 coefficient is about -1.404 , which fully verifies the authenticity of the H1 (hypothesis 1) environmental Kuznets curve (EKC), that is, the impact of economic development level (PGDP) on environmental pollution shows an inverted U-shaped "When the economy develops to a certain level, it will help to improve environmental pollution."

Inspired by model (2), model (3) changed the squared term of GDP per capita to the squared term of industrial agglomeration (IAG2) to verify whether there is a nonlinear relationship between industrial agglomeration and environmental pollution. The results show that: The influence coefficient of $\ln I A G 2$ on sulfur dioxide emissions is negative, similar to model (2), which fully shows that there will be an "inverted U-shaped" curve relationship between environmental pollution and industrial agglomeration due to different aggregation levels. When the threshold value is 1.06, Industrial agglomeration will play an important role in improving environmental pollution. Specifically, when the industrial agglomeration level is lower than the threshold of 1.06, the capacity expansion leads to the resource consumption rate exceeding the resource regeneration rate and environmental carrying capacity, and the environmental pollution continues to deteriorate; and when the industrial agglomeration level is raised to a certain level, the industrial agglomeration The technology spillover effect is obvious, which promotes the technological innovation of the enterprise, and the production efficiency and management level are also improved.. The industrial agglomeration triggers the economies of scale, so the environment can improved.

Model (4) introduced the interaction term of industrial agglomeration and technological innovation (IAG.INN) and found that the coefficient of the variable is negative, indicating that the correlation effect between industrial agglomeration and technological innovation can reduce environmental pollution to a certain extent, fully demonstrating In this paper, the necessity of adding technological innovation elements in the model of industrial agglomeration and environmental pollution, H2 (hypothesis 2) can be verified.

Model (5) introduces the squared term of industrial agglomeration (IAG2) and the interaction term of industrial agglomeration and technological innovation (IAG.INN). At this time, the threshold value changes to 1.026 $\left(\mathrm{e}^{\wedge}\left(0.13^{*} 2^{*} 0.10\right)\right)$, the technical innovation element It can really affect the inflection point value of industrial agglomeration to improve the degree of environmental pollution, that is, the threshold value of "inverted U-shaped curve". This suggests that we can try to reduce the inflection point value of the enterprise by improving the technological innovation ability, so that the conditions of the positive externality of the aggregate greater than the negative externality of the environment can be relaxed.

Model (6) introduces all the control variables to test the stability of the model. Observed data can found that the variables have not changed too much, the symbols are consistent, and the models and variables are significant.

\section{CONCLUSIONS AND POLICY RECOMMENDATIONS}

\section{A. Conclusion}

This paper takes the industrial agglomeration and technological innovation impact on the environment as the starting point, and uses the panel data of 30 provinces in China from 1998 to 2014 to conduct empirical analysis to explore the level of industrial agglomeration, the level of technological innovation, and the relationship between industrial agglomeration and technological innovation. The effect of the effect on environmental pollution, explore the complex nonlinear relationship between industrial agglomeration and the environment, test the key role of technological innovation in the mechanism of industrial agglomeration on environmental pollution, and determine the important role of technological innovation in energy conservation and emission reduction. corresponding to the hypothesis one by one summed up the following conclusions:

- The environmental Kuznets curve (EKC) has authenticity, and the relationship between economic development level and regional environment shows an "inverted U-shaped" curve.

- Under the new normal state, the relationship between industrial agglomeration and regional environment in China also follows the environmental Kuznets curve, which rises first and then falls. When the location entropy index crosses the threshold of 1.06, industrial agglomeration will improve the environmental pollution. From the location index of the past 30 provinces in China, most of them are between 0.8 and 1 , at the threshold. On the left, it means that under the current situation, the level of industrial agglomeration in various provinces has not yet reached the "threshold value" that can improve environmental pollution.

- Technological innovation has a significant impact on pollution emissions, and full use of technological innovation can more effectively carry out energy conservation and emission reduction work. In addition, the impact of technological innovation on the threshold value cannot ignored. It is also one of the channels to improve the environment by 
accelerating technological innovation and lowering the threshold of industrial agglomeration.

\section{B. Policy Recommendations}

- Implementing the innovation-driven strategy should promote the industrial clustering of regional industries in real time, truly bring into play the agglomeration effect of the industry, and achieve the simultaneous improvement of regional environmental quality and economic development. Industry agglomeration has a significant role in promoting enterprise innovation decision-making and new product output in the region, and brings innovation benefits and technological spillover effects of regional development. Therefore, the government should increase financial subsidies and policy inclinations for enterprises' scientific and technological innovation funds, change the existing labor-intensive and low-end processing development models, and effectively promote the improvement of industrial agglomeration levels in the region. Implement technological innovation, break through the bottleneck of industrial agglomeration development, and accelerate the breakthrough of the "threshold value" of industrial agglomeration in inland areas.

- Increase financial support for enterprise technology innovation, change the existing labor-intensive and low-end processing development models in each province, accelerate the promotion of high-end industrial agglomeration and industrial chain upgrading, and rely on technological progress to break through the bottleneck of agglomeration development. Accelerate the breakthrough of industrial agglomeration to bring into play the "threshold value" of environmental positive externalities, achieve a win-win situation of agglomeration development and environmental pollution; In-depth reform, encourage enterprises to innovate in technological innovation, encourage enterprises to cooperate with universities and scientific research institutions, and use technology, industry and research alliances to improve technological innovation. Efficiency, promote the transformation of scientific and technological achievements; Vigorously develop the service industry in coastal provinces, improve the level of high-end service industry agglomeration and service industry, not only enhance the attractiveness of foreign investment, but also provide support for the development of local enterprises.

- Improve the access threshold mechanism of the agglomeration area, and increase the assessment of the technological innovation capability and the discharge regulation capacity of enterprises entering the agglomeration area. The limitation of the environmental access threshold in the agglomeration area depends on the ability of the enterprise to innovate in science and technology. The enterprises in the agglomeration area must have strong scientific and technological innovation capabilities, and the R\&D expenditures occupy a large proportion of the total expenditure and the ability to upgrade production technology.

\section{REFERENCES}

[1] Liu Shucheng. Modern Economic Dictionary. Fenghuang Publishing House, 2005.

[2] Qiu Zhaoyi. The impact of international vertical specialization on China's environment. Academic Forum, 2012, (3): 121-125.

[3] Zhang Ke, Wang Dongfang. Interaction between economic agglomeration and environmental pollution and spatial spillover. China Industrial Economy, 2014, (6): 70-82.

[4] Liu Manfeng, Xie Yujin. Research on the convergence of provincial economic agglomeration and pollution agglomeration. Economic Geography, 2014, 4(4): 25-32.

[5] Yang Liqiong, Li Weina. Agglomeration externalities, environmental technology efficiency and energy conservation and emission reduction. Soft Science, 2011, 25(9): 14-19.

[6] Liu Xiping, Song Deyong. The impact of urban industrial agglomeration on urban environment. Urban Issues, 2013, (3): 9-16.

[7] Li Yonggang, Zhang Peng. Industrial agglomeration exacerbates China's environmental pollution: empirical evidence from China's provincial level. Journal of Huazhong University of Science and Technology (Social Science Edition), 2013, 27(5): 97-106.

[8] Li Yule. Empirical Analysis of Marketization, Industrial Agglomeration and Environmental Pollution. Statistical Research, 2014, 31(8): 39-45.

[9] JIANG Fuxin, WANG Zhujun, BAI Junhong. The dual effect of environmental regulation on technological innovation-an empirical study based on dynamic panel data of Jiangsu manufacturing industry [J]. China Industrial Economy, 2013, (7): 4445 